\title{
MOLGENIS/OMX for multi-omics and personalized medicine
}

\author{
Morris Swertz ${ }^{*}$ K. Joeri van der Velde \\ From 1st Clinical Research Informatics (CRI) Solutions Day \\ Duesseldorf, Germany. 26-27 May 2014
}

\section{Characterisation}

Tool, genomics, personalized medicine, meta-data, data, annotation, integration, visualization, open source/free.

\section{Description}

MOLGENIS/omx [1] is a generic toolbox for multi-omics and personalized medicine studies such as EU-Panacea, EU-BioSHaRE, EU-BioMedBridges, NL-String of Pearls, and CTMM/Triumph. OMX comes with a simple Excel format to upload data; a powerful data explorer to find and filter data; a genome browser; an $\mathrm{R}$ statistical programming interface for bioinformaticians and integrated annotation tools for Chembl, Ensembl, OMIM, etc. Increasingly bigger datasets are required for epidemiological and genetic analysis and hence, it has 'big data' stores connected using VCF and Elastic searches. MOLGENIS/omx gave rise to a variety of web applications in the life science domain, including omics data warehouses, patient mutation registries, and clinical data integration platforms. For example, the WormQTL ${ }^{\mathrm{HD}}$ database [2]

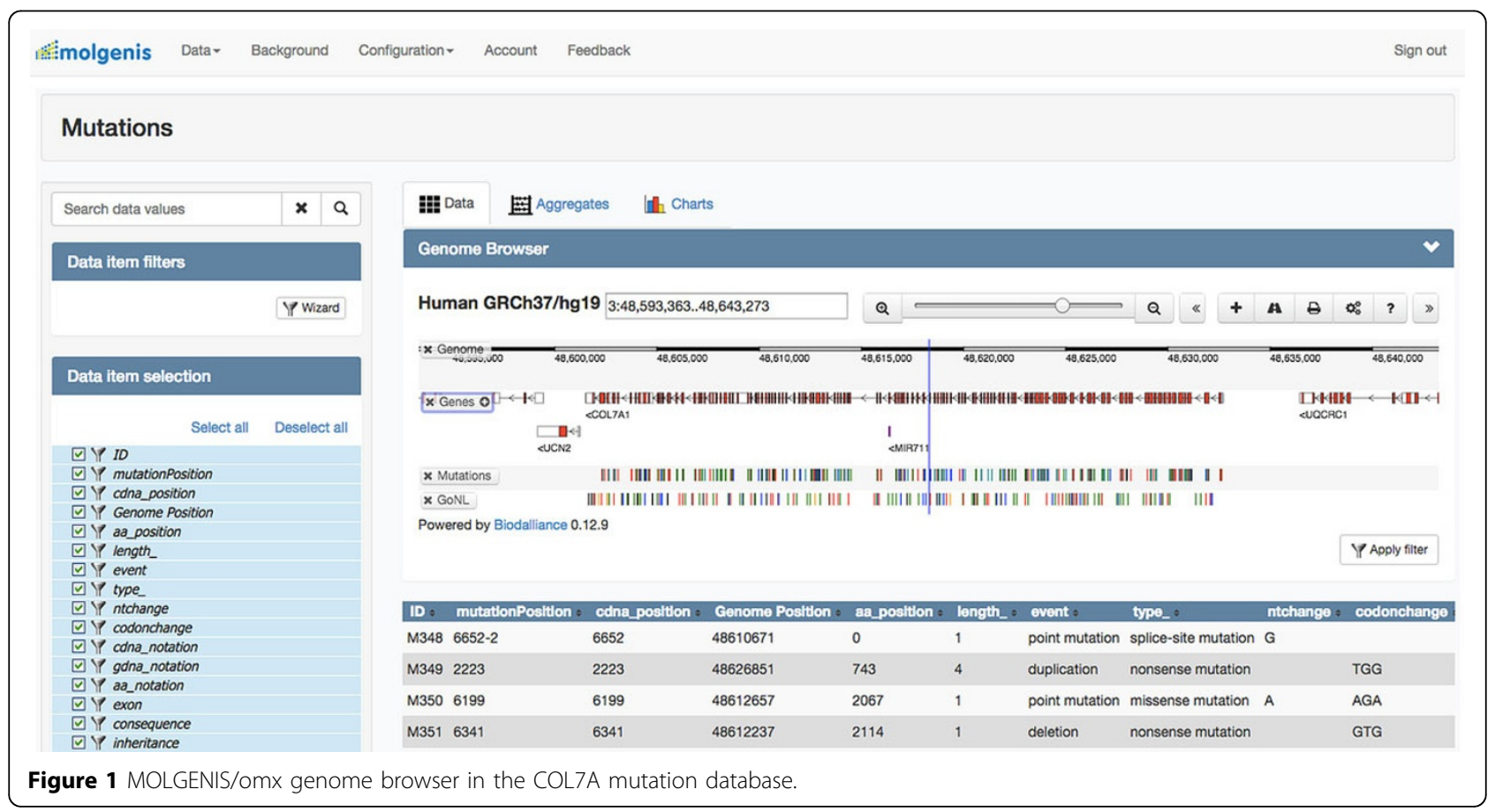

\footnotetext{
* Correspondence: m.a.swertz@rug.nl

Genomics Coordination Center, Department of Genetics, University Medical Center Groningen, 9700 RB Groningen, the Netherlands
} 
contains over 60 omics data sets contributed by the international $C$. elegans research community. Patient registries such as those developed for MVID [3], Dystrophic EB, and CHARGE syndrome enable clinicians to enter data about patient phenotypes and causal mutations. MOLGENIS/omx most recent application is to facilitate interpretation of the massive amounts of genomics data, including eQTL pathogenicity predictions, and/or clinical interpretation of NGS data in research consortia and clinical labs.

\section{Status of development}

Version 1.2.0.

\section{Users}

10 known installations.

\section{Links}

http://github.com/molgenis/molgenis, http://www.molgenis.org

Published: 22 May 2015

\section{References}

1. Swertz MA, Dijkstra M, Adamusiak T, van der Velde JK, Kanterakis A, Roos ET, et al: The MOLGENIS toolkit: rapid prototyping of biosoftware at the push of a button. BMC Bioinformatics 2010, 11(Suppl 12):S12.

2. Van der Velde KJ, de Haan M, Zych K, Arends D, Snoek LB, Kammenga JE, et al: WormQTLHD - a web database for linking human disease to natural variation data in C. elegans. Nucleic Acids Res 2014, 42(Database issue):D794-D801.

3. Van der Velde KJ, Dhekne HS, Swertz M, Sirigu S, Ropars V, Vinke PC, van ljzendoorn SCD, et al: An overview and online registry of microvillus inclusion disease patients and their MYO5B mutations. Human Mutation 2013, 34(12):1597-1605.

doi:10.1186/2043-9113-5-S1-S5

Cite this article as: Swertz and van der Velde: MOLGENIS/OMX for multiomics and personalized medicine. Journal of Clinical Bioinformatics 2015 5(Suppl 1):S5
Submit your next manuscript to BioMed Central and take full advantage of:

- Convenient online submission

- Thorough peer review

- No space constraints or color figure charges

- Immediate publication on acceptance

- Inclusion in PubMed, CAS, Scopus and Google Scholar

- Research which is freely available for redistribution

Submit your manuscript at www.biomedcentral.com/submit 